\title{
Daily Exercise for Anti-Obesity Anti-Diabetes Lifestyle
}

\section{Akbar Nikkhah* \\ Department of Animal Sciences, University of Zanjan, Iran}

*Corresponding author: Akbar Nikkhah, Department of Animal Sciences, Faculty of Agricultural Sciences, University of Zanjan, Chief Highly Distinguished Professor, Foremost Principal Highly Distinguished Elite-Generating Scientist, National Elite Foundation, Iran, E-mail: anikkha@yahoo.com

\section{Perspective \\ Volume 2 Issue 3}

Received Date: August 21, 2017

Published Date: August 28, 2017

DOI: $10.23880 /$ doij-16000164

\section{Abstract}

This article describes the importance of daily exercise in securing a healthy lifestyle. Weekly expression of requirements for exercise can no longer meet real standards for a healthy lifestyle. Since eating occurs daily and indeed multiple times daily, exercise must also occur daily in concert with eating. This would allow cells to live in normal chronobiological cycles.

Keywords: Exercise; Eating; Lifestyle; Daily routine

The objective of this article was to describe the chronobiological significance of daily exercise in securing a healthy lifestyle. There is a principle that substrate intake and oxidation should be synchronized for body to maintain a healthy state. Thus, it is not logical to eat every day and exercise only once or twice a week. Since eating occurs daily, exercise must also occur daily. It is only with such a close relation between eating and exercise that body can tolerate the nutrients that it consumes [1-5].

A critique towards the daily exercise would be the highly occupied and stressful lifestyle in the modern age. Nonetheless, to keep the body far from stresses and diseases, time has to be made for daily exercise. Compromise must be made and work hours must be reduced at least to some extent to allow the daily exercise to be scheduled in daily routines.

The nature of daily exercise needs to be adequately extensive. Sweating must occur and heart beating must rise significantly. This requires running, swimming, jumping and/or climbing. Slow walking may not be enough in stimulating healthy metabolic and oxidative reactions [5-8]. Evening could be an optimal time for daily exercise in forming a healthy lifestyle [2,7]. For evening to prove effective in healthful timing of exercise, major food meals must be taken earlier in the day (e.g., morning) with minor eating later during evening and night $[1,2,8]$.

\section{Conclusion}

This article described the significance of daily physical activity in forming a healthy lifestyle.

\section{References}

1. Nikkhah A (2016) Orchestrating Eating and Exercise to Improve Endocrinology: An Innovation against Diabetes. Curr Res Diabetes Obes J 1(2): CRDOJ.MS.ID.555558.

2. Nikkhah A (2016) Shattered Obesity by Morning Eating and Evening Exercise. Adv Obes Weight Manag Control 4(6): 00111.

3. Nikkhah A (2016) Balance Eating and Exercise to Prevent Obesity: Regularity Required. Adv Obes Weight Manag Control 4(6): 00110.

4. Nikkhah A (2016) A Simple Global Exercise Program to Overcome Obesity. Adv Obes Weight Manag Control 4(5): 00108.

5. Nikkhah A (2016) Running a pragmatic anti-cancer probiotic. J Prob Health 4: e124. 


\section{Diabetes and Obesity International Journal}

6. Nikkhah A (2016) Evening Avoidance of Large Meals alongside Evening Exercise to Improve Maternal and Child Health. Clinics Moth Child Health 13: 224.

7. Nikkhah A (2016) Morning Eating and Evening Exercise: Towards an Anti-Cancer Lifestyle. J Cancer Prev Cur Res 4(4): 00127.
8. Nikkhah A (2015) Synchronized Rhythms of Exercise and Eating: A Novel Public Program to Reduce Maternal and Pediatric Diabetes. Maternal and Pediatric Nutrition Journal 1: e101. 